\title{
Humidity sensor based on tapered single mode fiber coated with a hydroxyethyl cellulose/poly-vinylidene fluoride composite
}

\author{
${ }^{1}$ Lokman A., ${ }^{1}$ Batumalay M., ${ }^{1,2}$ Harun S. W. and ${ }^{1}$ Arof H. \\ ${ }^{1}$ Department of Electrical Engineering, Faculty of Engineering, University of \\ Malaya, 50603 Kuala Lumpur, Malaysia \\ ${ }^{2}$ Photonics Research Centre, University of Malaya, 50603 Kuala Lumpur, Malaysia
}

Received: 01.04.2014

\begin{abstract}
A simple humidity sensor is suggested basing on a tapered single-mode fibre coated with a mixed polymer composite hydroxyethyl cellulose/polyvinylidene fluoride. The tapered fibre produced by an etching technique and coated with a humidity-sensitive cladding creates intermodal interference which enables detecting humidity changes. The performance of the sensor is studied for the two fibre diameters, 50 and $87.5 \mu \mathrm{m}$. As the relative humidity increases, the interference spectrum shifts towards longer wavelengths. The highest sensitivity, $0.0116 \mathrm{~nm} / \%$, is obtained at the smallest tapered-fibre diameter of $50 \mu \mathrm{m}$, with the linearity being more than $98.20 \%$.
\end{abstract}

Keywords: fibre-optic sensors, humidity sensors, relative humidity, hydroxyethyl cellulose/polyvinylidene fluoride

PACS: 42.81.Qb, 42.81.Pa, 92.60.Jq

UDC: $535.417+53.093+681.7 .068$

\section{Introduction}

Recently, much effort has been poured into development of various fibre-optic sensors, which reveal many important advantages. Compared to conventional electric-based sensors, the fibreoptic ones prove to be cheap and applicable in hazardous environments or the places where immunity to electromagnetic interference is required. They also offer various possibilities for multiplexing a large number of different sensors (e.g., those used for detecting temperature, $\mathrm{pH}$, humidity, high magnetic field, displacement, pressure and acceleration) into the same optical fibre, thus removing a need in multiply cabling required in traditional electronic sensing [1]. Likewise, tapered fibres have also attracted a considerable interest in the recent years since they exhibit a number of exciting properties [2-4]. The tapered fibres manifest a strong evanescent field that travels along the cladding, which can be manipulated for different sensing applications. For instance, Muto et al. [5] have demonstrated humidity sensors, which are based on the reversible absorption of water from an ambient atmosphere into a porous thin-film interferometer sitting at the tapered fibre. The water absorbed from the ambience changes the refractive index of the thin films and subsequently transforms a strongly lossy fibre into a perfect lightguide. The humidity sensing has also been suggested using a tapered fibre with an agarose gel [6].

Earlier a humidity sensor that employs a tapered plastic optical fibre coated with a mixture of hydroxyethyl cellulose/polyvinylidene fluoride (HEC/PVDF) polymers has been demonstrated basing on the intensity modulation technique [7]. Notice that this technique requires periodic recalibration to maintain the accuracy. In the present study, we study a new optical-fibre humidity sensor based on a wavelength shift occurring in a tapered single-mode fibre (SMF) coated with the 
HEC/PVDF composite. The composite coating changes its optical properties in response to the changes of the relative humidity of its surrounding. The performance of the sensor is investigated for different diameters of the tapered fibre.

\section{Experimental arrangement}

A number of media such as polyimide, crystal violet, porous silica xerogel [8], agarose, and a variety of methyl polymers could be used to coat tapered fibres for various sensing applications, including humidity measurements. In this work, a mixture of HEC and PVDF was chosen as a sensing material since it is inexpensive and relatively simple to prepare. At first, $1 \mathrm{~g}$ of the PVDF powder $\left(M_{w}=275,000\right.$ by GPC) was dissolved in $120 \mathrm{ml}$ of dimethyl sulfoxide and $100 \mathrm{ml}$ of distilled water. Then $4 \mathrm{~g}$ of the HEC was added to the PVDF solution. The mixture was continuously stirred at the room temperature for about $10 \mathrm{~h}$ to generate three-dimensional structure of the mesh gel (hydrogel). The dimethyl sulfoxide solvent was used because the HEC is only soluble in water, while the PVDF is not. Fig. 1 shows the image of the HEC/PVDF solution and the microscopic image of the HEC/PVDF composite.


Fig. 1. (a) Image of HEC/PVDF solution and (b) microscopic image of HEC/PVDF composite.

A tapered fibre was prepared from a standard communication-grade SMF with a chemical etching technique, using a solution of hydrofluoric acid (47\%) for about 10 and $30 \mathrm{~min}$, in order to obtain different diameters. The SMF had the diameters of core and initial cladding equal to 8.3 and $125 \mu \mathrm{m}$, respectively. The coating of a short section of the fibre (about several centimetres in length) was removed prior to the etching process. Next, the HEC/PVDF composite solution thus prepared was gently dropped onto the etching fibre, using a syringe, and was left to dry for $48 \mathrm{~h}$. Fig. 2a, b and c show the microscopic images of the SMF fibre before and after 30 min- and 10 min-long etchings performed with the aid of the hydrofluoric acid solution. Finally, Fig. 2d shows the etched fibre after its coating with the HEC/PVDF composite.
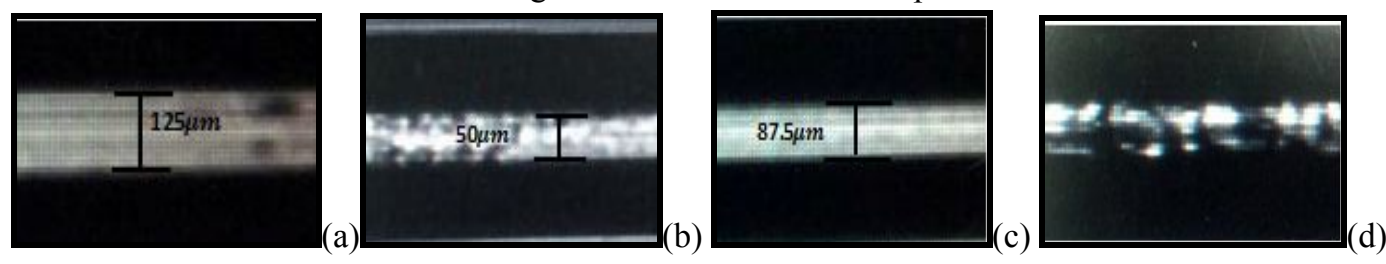

Fig. 2. Microscopic images of our SMF taken (a) before etching (the initial diameter is $125 \mu \mathrm{m}$ ) and after etchings for (b) $30 \mathrm{~min}$ (the final diameter is $50 \mu \mathrm{m}$ ) and (c) $10 \mathrm{~min}$ (the final diameter is $87.5 \mu \mathrm{m}$ ). Panel (d) shows etched SMF coated with the HEC/PVDF composite.

Ukr. J. Phys. Opt. 2014, Volume 15, Issue 2 




Fig 3. Experimental setup of our relative humidity sensor: abbreviation 'ASE' means an amplified spontaneous emission and 'OSA' an optical spectrum analyzer.

Fig. 3 depicts the experimental setup of our sensor aimed at detecting changes in the relative humidity using the tapered SMF coated with the HEC/PVDF composite. The input and output ports of the microfibre are connected to a source of amplified spontaneous emission and an optical spectrum analyzer, respectively. A sensed probe is placed into a sealed chamber containing a dish filled with a saturated salt solution. Exposing the HEC/PVDF composite to the relative humidity changes inside the chamber produces variations in the optical transmission spectrum. In the experiment, the performance of our sensor has been investigated for the relative humidity changes ranging from 60 to $80 \%$, using a 1365 data-logging humidity-temperature meter.

\section{Results and discussion}

In this work, the SMF diameter has been sharply reduced by chemical etching to allow the fundamental mode and the higher-order modes to enter and propagate inside the core. As the light propagates through an air-cladding interface in the taper-waist region, the SMF is converted into a multi-mode fibre due to a large difference between the refractive indices of the air and the glass. These modes then recombine at the output end of the tapered fibre. The consequence of the backand-forth coupling between the single mode of the untapered fibre and the two (or more) modes of the tapered fibre is oscillations of spectral response of the tapered fibre. This gives rise to a periodic behaviour of the transmission spectrum. The velocities and the phases of the interfering modes at the air-cladding interface are sensitive to the change in the refractive index of the surrounding medium.

Hence, various sensors can be implemented by monitoring the shifts occurring in the transmission spectrum of the modal interferometer. However, we have observed that the spectral response of the tapered fibre itself remains unchanged with varying humidity. This is the reason why the humidity measurements performed in this work are based on the tapered fibre coated with the humidity-sensitive layer such as the HEC/PVDF composite. Fig. 4 displays the transmission spectra of the amplified spontaneous emission for the tapered SMF coated with the HEC/PVDF composite, which have been measured at different relative humidities ranging from 60 to $80 \%$. The characteristics of the sensor are investigated for the cases of two tapered fibres with the diameters of 50 and $87.5 \mu \mathrm{m}$. As seen from Fig. 4a and Fig. 4b, the transmission spectra for the 
both fibre diameters shift from shorter wavelengths to longer ones with increasing humidity. As an example, the wavelength corresponding to the transmittance maximum at the diameter of $87.5 \mu \mathrm{m}$ shifts from 1554.56 to $1554.78 \mathrm{~nm}$ as the relative humidity increases from 60 to $80 \%$. The wavelength shift becomes larger as the diameter of the fibre is reduced.
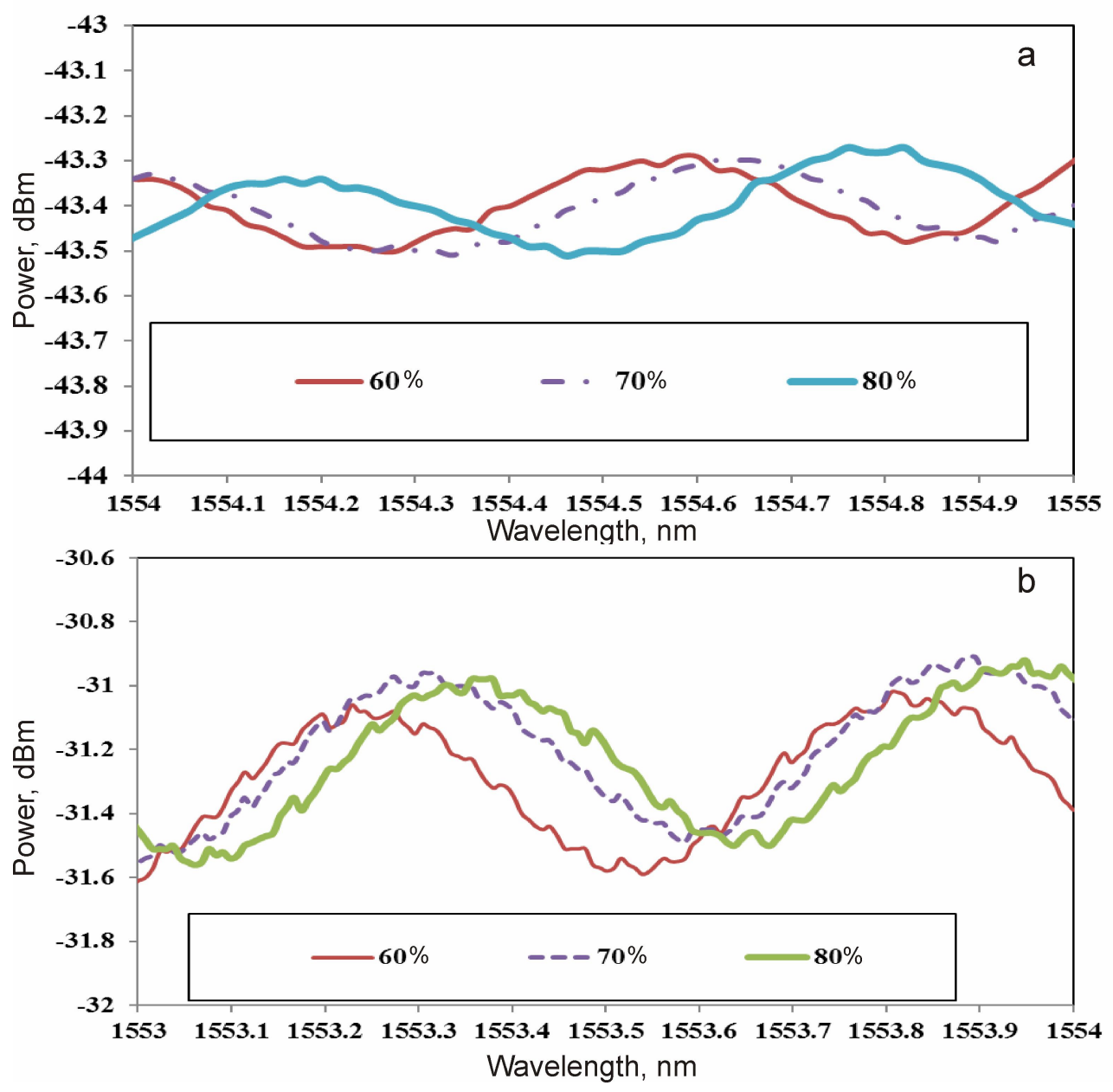

Fig. 4. Transmission spectra of our sensor measured at different relative humidity percentages (60, 70 and 80$)$ for the cases of tapered-fibre diameters being equal to (a) $50 \mu \mathrm{m}$ and (b) $87.5 \mu \mathrm{m}$.

Fig. 5 shows the dependences of the wavelength corresponding to the transmittance maximum upon the relative humidity measured for the HEC/PVDF-coated tapered fibres of different diameters. As seen from Fig. 5, the wavelength corresponding to the transmittance maximum shifts almost linearly towards longer wavelengths with increasing relative humidity. An increase in the humidity increases the refractive index of the HEC/PVDF layer and so increases the overall cladding refractive index. In its turn, this changes the velocity and the phase of the two modes interfering at the air-cladding interface. This effect is transformed into a shift of the comb-like transmission spectrum observed at the output of the tapered fibre. The sensitivity of the sensor depends strongly on the fibre diameter which determines the effective refractive index of the cladding. The highest sensitivity, $0.0116 \mathrm{~nm} / \%$, is obtained at the smallest diameter, $50 \mu \mathrm{m}$, with the linearity being not less than $98.20 \%$. The sensitivity degrades down to $0.0065 \mathrm{~nm} / \%$ as the diameter increases up to $87.5 \mu \mathrm{m}$. The performance characteristics of our sensor are summarized in Table 1.

Ukr. J. Phys. Opt. 2014, Volume 15, Issue 2 


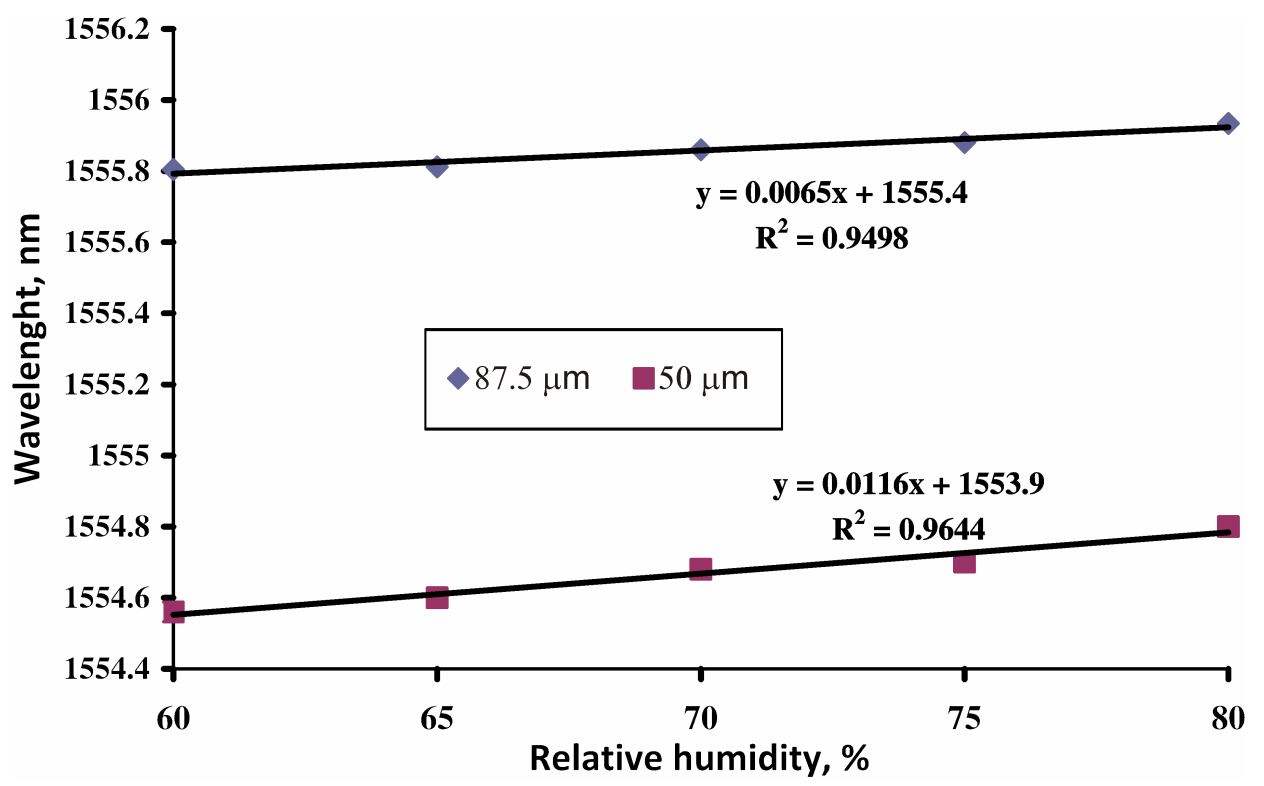

Fig. 5. Shifts observed for the wavelength corresponding to the transmittance maximum with increasing relative humidity.

Table 1. Performance characteristics of our humidity sensor dependent on conditions of preparation of the basic optical fibre.

\begin{tabular}{|c|c|c|}
\hline $\begin{array}{c}\text { Performance } \\
\text { characteristics }\end{array}$ & $\begin{array}{c}\text { SMF etching during } 30 \mathrm{~min} \text {; the } \\
\text { diameter } 50 \mu \mathrm{m}\end{array}$ & $\begin{array}{c}\text { SMF etching during } 10 \mathrm{~min} \\
\text { the diameter } 87.5 \mu \mathrm{m}\end{array}$ \\
\hline Sensitivity $(\mathrm{nm} / \%)$ & 0.0116 & 0.0065 \\
\hline Linearity (\%) & 98.20 & 97.45 \\
\hline
\end{tabular}

\section{Conclusion}

We have suggested a simple humidity sensor using a microstructure-tapered optical fibre coated with the HEC/PVDF composite. The tapered fibre is fabricated with the etching method. In order to obtain two different fibre diameters, we have used the hydrofluoric acid solution (47\%) acting for 30 and $10 \mathrm{~min}$. As the relative humidity increases, the optical transmittance wavelength corresponding to the transmittance maximum shifts towards longer light wavelengths. The microfibre with the diameter of $50 \mu \mathrm{m}$ has the sensitivity of $0.0116 \mathrm{dBm} / \%$ and the linearity of more than $98.20 \%$. For the probing fibre with the diameter of $87.5 \mu \mathrm{m}$, the sensitivity of $0.0065 \mathrm{dBm} / \%$ is achieved, with the linearity not less that $97.5 \%$. Hence, our experiments demonstrate that the HEC/PVDF-coated fibre reacts sharply to the humidity changes, via the changes in the effective cladding refractive index, and so proves its capability as a relativehumidity sensor.

\section{References}

1. Yeo L, Sun T and Grattan K T V, 2008. Fibre-optic sensor technologies for humidity and moisture measurement. Sens. Actuators A: Phys. 144: 280-295.

2. Rahman H A, Harun S W, Yasin M, Phang S W, Damanhuri S S A, Arof H and Ahmad H, 2011. Tapered plastic multimode fiber sensor for salinity detection. Sens. Actuators A: Phys. 171: $219-222$. 
3. Muhammad M Z, Jasim A A, Ahmad H, Arof H and Harun S W, 2013. Non-adiabatic silica microfiber for strain and temperature sensors. Sens. Actuators A: Phys. 192: 130-132.

4. Harun S W, Lim K S, Damanhuri S S A and Ahmad H, 2011. Microfiber loop resonator based temperature sensor. J. Eur. Opt. Soc. 6: 11026.

5. Muto S, Suzuki O, Amano T and Morisawa M, 2003. A plastic optical fibre sensor for realtime humidity monitoring. Meas. Sci. Technol. 14: 746-750.

6. Bariain C, Matias I R, Arregui F J, and López-Amo M, 2000. Optical fiber humidity sensor based on a tapered fiber coated with agarose gel. Sens. Actuators B: Chem. 69: 127-131.

7. Estella J, de Vicente P, Echeverría J C and Garrido J J, 2010. A fibre-optic humidity sensor based on a porous silica xerogel film as the sensing element. Sens. Actuators B: Chem. 149: $122-128$.

8. Batumalay M, Lokman A, Ahmad F, Arof H, Ahmad H and Harun S W, 2013. Tapered plastic optical fiber coated with HEC/PVDF for measurement of relative humidity. Sens. J. IEEE. 13: $4702-4705$.

Lokman A., Batumalay M., Harun S.W. and Arof H. 2014. Humidity sensor based on tapered single mode fiber coated with a hydroxyethyl cellulose/poly-vinylidene fluoride composite. Ukr.J.Phys.Opt. 15: 96 - 101.

Анотація. В роботі запропонований простий сенсор вологості, базований на конічному одномодовому волокні, покритому змішаним полімерним композитом гідрооксиетилиелюлози/полівініліденфториду. Конічне волокно, виготовлене травленням $i$ покрите оболонкою, чутливою до вологості створюе міжмодову інтерференцію, яка дозволяє реєструвати зміни вологості. Характеристики сенсора досліджувалась для двох діаметрів волокна: 50 і 87,5 мкм. При зростанні вологості спектр інтерферениії зміщався в область довгих довжин хвиль. Найвища чутливість 0,0116 нм/\%, була отримана для волокна з меншим діаметром 50 мкм, з лінійністю не гіршою ніж 98,20\%. 